\title{
ECONOMIA CAMPONESA E RESISTÊNCIA TERRITORIAL NO ASSENTAMENTO CHICO MENDES - PE/BRASIL
}

\author{
ECONOMÍA CAMPESINA Y RESISTENCIA TERRITORIAL EN \\ EL ASENTAMIENTO DE CHICO MENDES - PE / BRASIL
}

Cláudio Ubiratan Gonçalves

Professor Titular do PPGEO/ UFPE claudio.ubiratan@ufpe.br

Alexandre Chaves Bezerra

Mestrando do PPGEO/UFPE xandino87@hotmail.com

Anamaria Melo Medeiros Mestre em Geografia pelo PPGEO/ UFPE meloanamariaa@gmail.com

Andrés Felipe Bernal Mestrando do PPGEO/ UFPE andres.felipe.br@gmail.com

\section{Izabela Cristina Gomes da Silva Doutoranda do PPGEO/ UFC izabela.cristinagomes@gmail.com}

Diego Felipe dos Santos Mestrando do PPGEO/ UFPE diego.felipeufpe@gmail.com

Maria Rosana da Costa Oliveira Doutoranda do PPGEO/UFPE rosanaoliveira87@gmail.com

Taíse dos Santos Alves Doutoranda do PPGEO/UFPE taisealves85@gmail.com

\section{Resumo}

Este artigo resulta do projeto internacional 'Entre la consolidación y la descomposición de las economías campesinas. Una lectura comparada de las experiencias de Brasil y Colombia ${ }^{1}$. Nessa primeira etapa, buscamos fazer um estudo acerca das unidades produtivas do assentamento rural Chico Mendes - PE a partir da perspectiva teórica Economia Camponesa. Para obtenção dos resultados utilizamos a metodologia MESMIS 
Economia camponesa e resistência territorial no assentamento Chico Mendes - PE/Brasil
Cláudio Ubiratan Gonçalves Alexandre Chaves Bezerra

Anamaria Melo Medeiros Andrés Felipe Bernal

Izabela Cristina Gomes da Silva

Diego Felipe dos Santos

Maria Rosana da Costa Oliveira Taíse dos Santos Alves

(Marco para Evaluación de Sistemas de Manejo de Recursos Naturales Incorporando Indicadores de Sustentabilidad) juntamente com pesquisa-participante de Brandão (2007). A partir dessas metodologias podemos verificar as estratégias de acesso aos 'mercados' utilizadas pelos camponeses do Assentamento rural Chico Mendes e como elas refletem na resistência territorial.

Palavras - chave: Economia Camponesa, território, resistência.

\section{Resumen}

Este artículo es el resultado del proyecto internacional 'Entre la consolidación y la descomposición de las economías campesinas. Una conferencia comparativa sobre las experiencias de Brasil y Colombia '. En esta primera lectura, buscamos hacer un estudio sobre las unidades productivas del asentamiento rural Chico Mendes - PE desde la perspectiva teórica de la Economía Campesina. Para obtener los resultados, utilizamos la metodología MESMIS (Marco para la evaluación de sistemas de gestión de recursos naturales que incorporan indicadores de sostenibilidad) junto con la investigación participante de Brandão (2007). A partir de estas metodologías podemos verificar las estrategias de acceso al mercado utilizadas por los campesinos del Asentamiento Rural Chico Mendes y cómo reflejan la resistencia territorial.

Palabras - llave: economía campesina, territorio, resistencia.

\section{Introdução}

A discussão acerca do campesinato tem se tornado cada vez mais contemporânea, frente o avanço do capitalismo sobre os territórios latino-americanos. Consideramos que os processos de luta pela terra, de produção prioritariamente para consumo próprio, de manejo da terra contrário ao manejo agroindustrial, de ajuda mútua e utilização de conhecimento popular tradicional fazem parte do cotidiano camponês deste início de século (XXI). 
Economia camponesa e resistência territorial no assentamento Chico Mendes - PE/Brasil
Cláudio Ubiratan Gonçalves Alexandre Chaves Bezerra

Anamaria Melo Medeiros Andrés Felipe Bernal

Izabela Cristina Gomes da Silva Diego Felipe dos Santos

Maria Rosana da Costa Oliveira Taíse dos Santos Alves

Por campesinato compreende-se uma diversa gama de formas sociais baseadas na tríade Terra, Família e Trabalho. Chayanov (1974) defende que o campesinato atua numa lógica distinta da capitalista. No modo de vida camponês, a família geralmente obtém os meios de produção enquanto que no modelo capitalista industrial, estes são propriedade de uma única pessoa ou de grupos político-econômicos, gerando assim a proletarização no campo. Quando há uma homogeneização da distribuição desses meios, o camponês torna-se um assalariado, gerador de mais-valia.

Contudo a partir do movimento contraditório e combinado do desenvolvimento capitalista sobre o campo, os camponeses coexistem com o modelo de produção agroindustrial. Assim os preços da terra (baseados no tamanho e qualidade), a formação do mercado de produtos agrícolas e a circulação de mercadorias (local, nacional, internacional) interferem no modo de produção camponês, seja positivamente ou não.

Entendemos que a inserção do campesinato no mercado aparece como uma forma de resistência, objetivando a manutenção da condição camponesa e a reprodução da vida. Dentro do âmbito camponês um dos elementos primordiais para conquista de autonomia e soberania alimentar é que os povos sejam capazes de produzirem seu próprio alimento, assim como participarem dos processos de comercialização.

Para Chayanov (1924) essa prática aparece no seio da produção camponesa quando os camponeses se organizam em grupos para auxiliar algum deles, que se encontre com dificuldades (financeiras ou de saúde). Como também para realizar trabalhos coletivos e suprir a força de trabalho em algumas famílias.

Segundo o autor no estilo de vida camponês a produção aumenta de acordo com as necessidades da família e não de acordo com as necessidades e demandas do mercado. Além disso, o campesinato tem a liberdade de estabelecer seus horários de trabalho e escolher a forma de trabalhar, o que caracteriza a flexibilidade dentro da unidade produtiva camponesa. Porém quando muitos camponeses precisam trabalhar em outras terras, como alternativa para complementar sua renda, tal flexibilidade encontra-se limitada.

Então consideramos que as unidades produtivas do Assentamento Rural Chico Mendes - PE/Brasil são estruturas e gerenciadas sob o viés da economia camponesa. 
Economia camponesa e resistência territorial no assentamento Chico Mendes - PE/Brasil
Cláudio Ubiratan Gonçalves Alexandre Chaves Bezerra

Anamaria Melo Medeiros Andrés Felipe Bernal

Izabela Cristina Gomes da Silva Diego Felipe dos Santos

Maria Rosana da Costa Oliveira Taíse dos Santos Alves

Nesse contexto Ploeg (2008) defende que é necessário repensar a condição camponesa, para explicar o modo camponês de fazer agricultura.

\begin{abstract}
A luta por autonomia que se realiza em um contexto caracterizado por relações de dependência, marginalização e privações. Essa condição tem como objetivo e se concretiza na criação e desenvolvimento de uma base de recursos autocontrolada e auto-gerenciada, a qual por sua vez permite formas de coprodução entre o homem (sic) e a natureza viva que interagem com o mercado, permitem a sobrevivência e perspectivas de futuro e se realimentam na base de recursos e a fortalecem, melhorando o processo de coprodução, fomentando a autonomia e, dessa forma, reduzem a dependência. (PLOEG, 2008, p.40).
\end{abstract}

Portanto a busca por autonomia aparece como fundante para a reprodução do modo de vida camponês e se materializa em estratégias de autogestão das unidades produtivas. Essa capacidade organizativa envolve vários aspectos como: armazenamento de sementes crioulas e água, criação de animais, produção, consumo, beneficiamento e venda de alimentos, relações de trabalho e com a natureza, parentesco estendido e elaboração de manifestações culturais.

Todavia dentro do contexto da modernização conservadora capitalista a condição camponesa aparece como meio de conseguir autonomia e melhorias socioeconômicas, frente à insegurança alimentar e às relações de dependência político-econômicas.

Os camponeses do assentamento Chico Mendes para garantir sua reprodução enquanto categoria social comercializam seus produtos de diferentes formas: 1) nas feiras livres; 2) por intermédio dos atravessadores; 3) estabelecem contratos comerciais com grupos econômicos e 4) na troca ou venda entre os camponeses do assentamento. Vale ressaltar que a produção camponesa apesar de ser comercializada em diversos âmbitos, tem enquanto objetivo prioritário o consumo familiar.

No primeiro ponto os produtores estão em contato direto com os consumidores, estabelecendo circuitos curtos de produção. Já no segundo o atravessador compra e revende os produtos por um preço maior, neste caso o camponês não estabelece contato direto com os consumidores finais. $\mathrm{O}$ terceiro ponto está relacionado às unidades produtivas onde plantam cana-de-açúcar, que é vendida exclusivamente à Usina Santa 
Economia camponesa e resistência territorial no assentamento Chico Mendes - PE/Brasil
Cláudio Ubiratan Gonçalves Alexandre Chaves Bezerra

Anamaria Melo Medeiros Andrés Felipe Bernal

Izabela Cristina Gomes da Silva Diego Felipe dos Santos

Maria Rosana da Costa Oliveira Taíse dos Santos Alves

Tereza. Enquanto na quarta forma verificamos as relações não capitalistas camponesas, materializadas como as trocas de produtos.

Então partindo da perspectiva de Teodor Shanin (1983), Duarte (2015), propõe fazer uma caracterização camponesa baseado em quatro caraterísticas: 1) Formas organizacionais: a família é a unidade básica dentro da organização social multidimensional. Nessa abordagem a organização coletiva do território é importante. 2) Formas de produção: o cultivo da terra é o meio para atender as necessidades de consumo camponesa. Porém o campesinato seja sem-terra ou provido dos meios de produção, pode vender sua força de trabalho. 3) Cultura: as relações com a natureza são fundamentais para compreensão da dimensão cultural dos povos camponeses. 4) A subalternização do campesinato pela lógica capitalista, relacionada à concentração fundiária e o desrespeito ao modo de vida camponês.

Assim segundo Shanin (1983) o ser camponês é composto também pela questão imaterial com a terra. Isso significa a identidade que cada comunidade mantém com o seu território dentro da relação sociedade-natureza. Como também destaca o fato de os sujeitos sociais exercerem um papel político decisivo na configuração das unidades produtivas camponesas.

\section{Utilização da abordagem MESMIS como metodologia}

As atividades que decorreram ao longo do estudo buscaram a obtenção de análise crítica a partir das diversas experiências camponesas encontradas, que passaram por processos históricos, sociopolíticos e culturais. Estando em constante transformação no tempo e no espaço.

A pesquisa foi realizada no Assentamento Chico Mendes, localizado no município de Tracunhaém, mesorregião Zona da Mata Norte do estado de Pernambuco - Brasil. Onde ocorreu a sistematização das experiências dos camponeses assentados, analisando os contextos político e social nos quais esses sujeitos estão inseridos.

Verificamos a sustentabilidade e autonomia e/ou dependência do assentamento rural frente à sua produção e às redes de comercialização. Estas são compreendidas na 
Economia camponesa e resistência territorial no assentamento Chico Mendes - PE/Brasil
Cláudio Ubiratan Gonçalves Alexandre Chaves Bezerra

Anamaria Melo Medeiros Andrés Felipe Bernal

Izabela Cristina Gomes da Silva Diego Felipe dos Santos

Maria Rosana da Costa Oliveira Taíse dos Santos Alves

presente pesquisa como as feiras (convencionais e agroecológicas), as relações com os atravessadores e com a Usina Santa Tereza.

Para compreendermos a economia camponesa e a autonomia dos territórios camponeses, utilizamos como metodologia parte da abordagem MESMIS (Marco para Evaluación de Sistemas de Manejo de Recursos Naturales Incorporando Indicadores de Sustentabilidad) juntamente com a perspectiva de pesquisa-participante de Brandão; Borges (2007). Com o intuito respectivamente, de traduzir princípios gerais de sustentabilidade em definições operacionais, indicadores e práticas no contexto da gestão de recursos naturais em comunidades camponesas (LÓPEZ-RIDAURA, MASERA, \& ASTIER, 2002).

A abordagem MESMIS é aplicável em sistemas de produção agrícola e florestal, procurando apontar de forma holística os limites e possibilidades de sustentabilidade do sistema sob as perspectivas político-econômica, sociocultural e ambiental.

Considera-se nessa metodologia atributos e os indicadores que englobam dimensões ambiental, econômica e sócio-política. A partir dos indicadores da tabela, correlacionando-os com cada atributo, encaminhamos juntamente com os camponeses assentados uma avaliação qualitativa das unidades produtivas.

Já a metodologia de base qualitativa abordada como pesquisa-participante na perspectiva de Brandão; Borges (2007), contendo entrevistas semiestruturadas com os camponeses assentados e vivência no assentamento Chico Mendes. Apesar das múltiplas dimensões que a pesquisa-participante abarca, optamos pela proposição de interação horizontalizada (sujeito-sujeito) entre pesquisadores e sujeitos sociais das situações investigadas, apreendendo o ponto de vista desses sujeitos em relação à realidade, para compreender suas visões (cosmovisões) de mundo.

Ao admitirmos as contribuições de Marangoni (2005), seguiremos um roteiro de entrevista com questões básicas, que se repetirão em diferentes situações, contudo passarão por certa flexibilidade e adaptabilidade de acordo com o desenvolvimento das entrevistas.

Com as respostas dos camponeses do Assentamento Chico Mendes aos questionamentos, analisamos as questões que envolvem o surgimento, disseminação e 
Economia camponesa e resistência territorial no assentamento Chico Mendes - PE/Brasil
Cláudio Ubiratan Gonçalves Alexandre Chaves Bezerra

Anamaria Melo Medeiros Andrés Felipe Bernal

Izabela Cristina Gomes da Silva Diego Felipe dos Santos

Maria Rosana da Costa Oliveira Taíse dos Santos Alves

manutenção das experiências verificadas, destacando a multiplicidade de manejos, ideais, estratégias e as diferenças existentes entre as unidades produtivas. Além das diferenças no acesso às políticas públicas e ao escoamento da produção, que são variáveis em cada unidade de produção.

Contudo a apreensão dessas características nos darão aspectos essenciais para compreendermos a economia camponesa contemporânea em Pernambuco - Brasil. Assim as múltiplas estratégias utilizadas pelos povos camponeses latino-americanos como: a organização em movimentos, a diversidade de manejos, a criação de tecnologias sociais, os processos de luta por terra/água/território, a autogestão, a manutenção de conhecimentos tradicionais populares, entre outras, estão relacionadas à condição camponesa como resistência ao avanço do capital no campo.

\section{Caracterização Socioterritorial da área: a monocultura canavieira em Pernambuco}

A inserção da cultura da cana-de-açúcar no estado de Pernambuco começou desde meados do processo de colonização pelo litoral. Com a expansão da monocultura canavieira e do processo de urbanização nesta área, chegou aos vales dos rios, assim se instalando em toda a região da Mata Atlântica. Devido às condições geomorfológicas (Mares de morros), climáticas (Tropical úmido - As) e pedológicas (Massapê) favoráveis. Além da facilidade para o escoamento da produção por conta da proximidade com os portos.

Apesar do processo de desenvolvimento da monocultura açucareira ter sido bastante consistente, historicamente o setor canavieiro de Pernambuco não conseguiu estabelecer um desenvolvimento dinâmico favorável como em outras partes do país. Visto que por razões históricas e políticas de sua formação territorial, com o passar dos anos, o poder continuou nas mãos das oligarquias latifundiárias.

Intensificando o monopólio sobre a terra e mantendo essa atividade agrícola e inibindo o surgimento de outras atividades econômicas. Logo observamos uma região onde o modelo de desenvolvimento consolidado está baseado na concentração de terras e riquezas, na destruição da natureza, na desigualdade socioterritorial, no conflito entre 
Economia camponesa e resistência territorial no assentamento Chico Mendes - PE/Brasil
Cláudio Ubiratan Gonçalves Alexandre Chaves Bezerra

Anamaria Melo Medeiros Andrés Felipe Bernal

Izabela Cristina Gomes da Silva

Diego Felipe dos Santos

Maria Rosana da Costa Oliveira Taíse dos Santos Alves

territorialidades.

Além de ter o Estado como principal incentivador desse desenvolvimento pautado pela economia canavieira. Tendo como consequências as condições precárias dos sujeitos sociais, que vivem nessa mesorregião, relacionadas à "ação desequilibrante e intempestiva do colonizador, quase cego às consequências (...) de plantar sempre mais cana e de produzir sempre mais açúcar." (Castro, 1984, p. 83).

A mesorregião da Mata Pernambucana (Figura 1) é composta atualmente por 43 municípios, dividindo-se em três microrregiões: Setentrional, Vitória de Santo Antão e Meridional.

Figura 1: Mapa Geopolítico de Pernambuco segundo sua divisão em mesorregiões

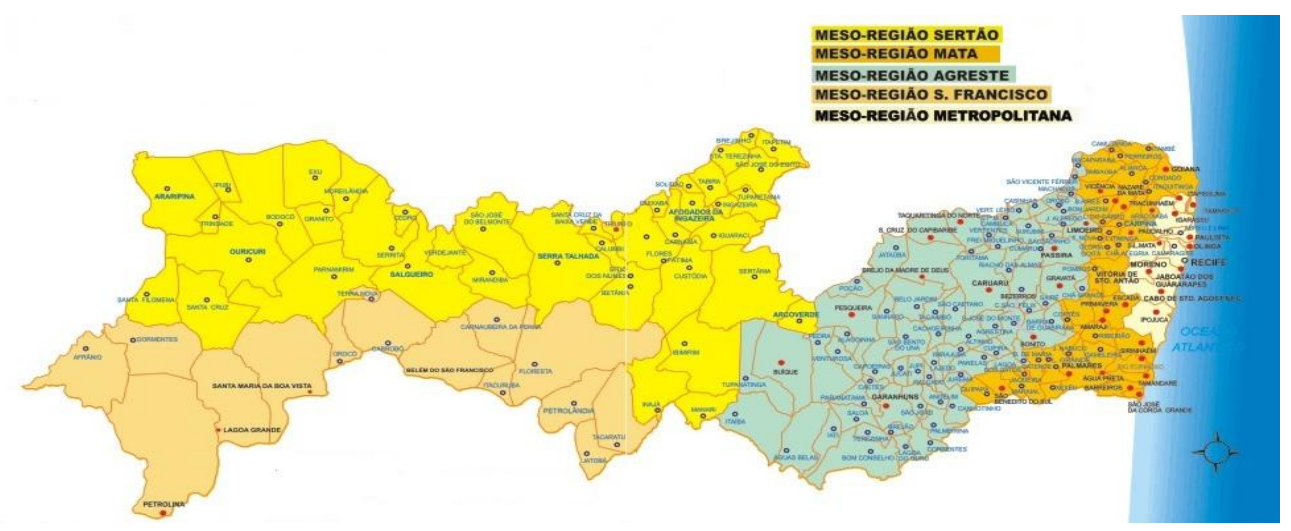

Fonte: Agência Condepe/Fidem, 2017.

A forma de exploração colonial a qual a região foi subordinada, baseada na monocultura, na exploração do trabalho alheio (inicialmente escravo e posteriormente assalariado, porém sem garantir os direitos trabalhistas), no uso degradante da terra, na coisificação dos sujeitos e na estrutura fundiária extremamente desigual. Materializandose na paisagem monotemática, quase que em sua totalidade, do "mar de cana", na economia e na sociedade.

Estruturada em classes, de forma rígida, ficando no ápice a nobreza, dita da terra, os grandes comerciantes e os altos funcionários reais que detinham o poder econômico e político. Essa classe era seguida de outra, 
Economia camponesa e resistência territorial no assentamento Chico Mendes - PE/Brasil
Cláudio Ubiratan Gonçalves Alexandre Chaves Bezerra

Anamaria Melo Medeiros Andrés Felipe Bernal

Izabela Cristina Gomes da Silva Diego Felipe dos Santos

Maria Rosana da Costa Oliveira Taíse dos Santos Alves

denominada média, formada por sitiantes, pequenos proprietários e prestadores de serviços, e de uma classe baixa, constituída por pessoas pobres que também prestavam serviços, mas de forma ocasional, muitas vezes gratuitos. Era a gente "sem eira nem beira", como se dizia, então. Finalmente havia a grande massa de escravos, em sua maioria africanos adquiridos no continente negro mediante escambo com fumo e aguardente, trazidos pelos tumbeiros para o país, onde eram comercializados. (ANDRADE et al., 2001, p.271).

Tais fatores nos permitem compreendermos por que ainda hoje a maior parte da população da Zona da Mata encontra-se economicamente estagnada, em condições sociais ruins e níveis de escolaridade muito baixos. Então a estrutura agrária existente desde o período colonial associada à monocultura da cana-de-açúcar é responsável pelo baixo nível de desenvolvimento humano (IDH) dessa mesorregião, que continua beneficiando a oligarquia patronal.

Nessa conjuntura na década de 70 o preço do açúcar perdeu estabilidade no mercado internacional, devido à queda do consumo mundial e à ascensão na Europa da produção do açúcar de beterraba, coincidindo com a alta dos preços do petróleo. Nesse período o Brasil encontrava-se com a balança comercial desfavorável e sem conseguir novos empréstimos em vistas à crise mundial. Então incentivou a produção nacional do agrocombustível álcool, que é derivado da cana-de-açúcar e lançou o Programa Nacional do Álcool, colocando-o como solução para a economia açucareira do país.

Na medida em que ocorreu no Brasil a modernização conservadora da agricultura, foram mantidos os latifúndios respaldados pelo projeto desenvolvimentista. Em contrapartida também houve o avanço dos processos de luta por terra protagonizados pelos movimentos sociais camponeses, como o Conselho Indigenista Missionário (CIMI) em 1972, a Comissão Pastoral da Terra (CPT) em 1975, o Movimento dos Trabalhadores Rurais Sem-Terra (MST) em 1984, e o Movimento dos Pequenos Agricultores (MPA) em 1990, enfatizando o direito à terra e o uso dos territórios por esses sujeitos.

Porém a partir dos anos 2000 o estado brasileiro continua seguindo a lógica desenvolvimentista, e juntamente com o capital privado patrocina o agronegócio. Nesse período o setor sucroalcooleiro vive um crescimento sustentado pelo aumento dos carros flex (com motores movidos à álcool e gasolina), pelos preços do petróleo e devido a maior 
Economia camponesa e resistência territorial no assentamento Chico Mendes - PE/Brasil
Cláudio Ubiratan Gonçalves Alexandre Chaves Bezerra

Anamaria Melo Medeiros Andrés Felipe Bernal

Izabela Cristina Gomes da Silva

Diego Felipe dos Santos

Maria Rosana da Costa Oliveira Taíse dos Santos Alves

demanda por agrocombustíveis. Estes eram vendidos midiáticamente como "bio"combustíveis ou combustíveis verdes. Advindos da crescente preocupação sobre a finitude do petróleo como "recurso" não renovável. Então em 2002 foi implementado o Programa Brasileiro de Biocombustíveis (Probiodiesel), como também se iniciou um processo de renovação do Programa Nacional do Álcool.

Todavia embora a base da economia da Zona da Mata ter se dado dentro da hegemonia da cana-de-açúcar. No entanto, há em curso uma "remodelação" mais latente na Mata Norte e na região de Vitória, fruto do Plano de Desenvolvimento do estado, iniciado pelo governo de Eduardo Campos (2007-2014). Quando foram implementados, a fim de dar subsídios para o projeto das "regiões de desenvolvimento", novos arranjos produtivos com a chegada de multinacionais do ramo alimentício em Vitória como a Kraft Foods, com a instalação do Pólo Farmacoquímico e da fábrica de automóveis Fiat na Mata Norte.

Apesar do projeto de "novos" arranjos produtivos e econômicos, estes estão sendo feitos em consonância com antigas questões engendradas desde a formação territorial da Zona da Mata, decorrentes da economia canavieira. Como verificamos nos dados do IBGE (2015) sobre produção agrícola municipal (Gráfico 1).

Gráfico 1: Área em hectares plantados com cana-de-açúcar em Pernambuco, 2015

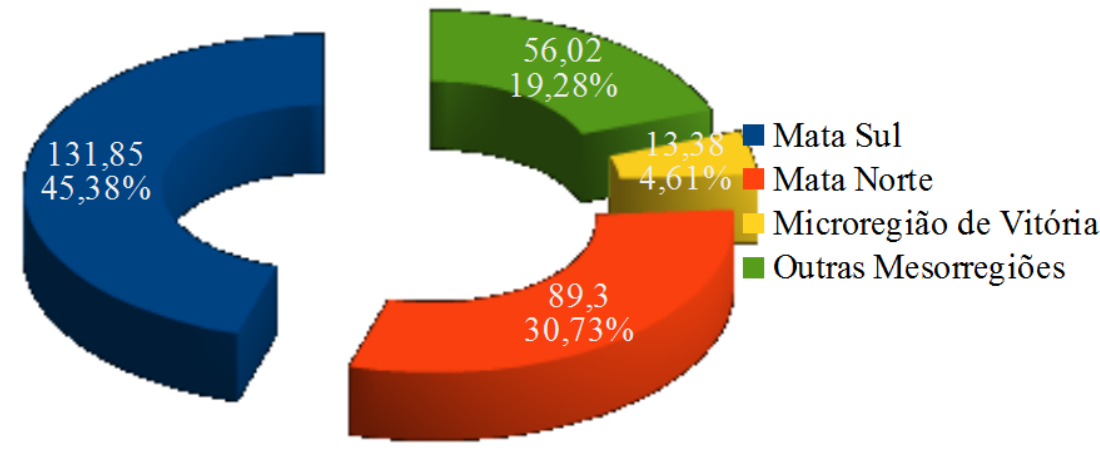

Fonte: Produção Agrícola Municipal - IBGE, 2015. Organização: Anamaria Medeiros - LEPEC, 2017. 
Economia camponesa e resistência territorial no assentamento Chico Mendes - PE/Brasil
Cláudio Ubiratan Gonçalves Alexandre Chaves Bezerra

Anamaria Melo Medeiros Andrés Felipe Bernal

Izabela Cristina Gomes da Silva

Diego Felipe dos Santos

Maria Rosana da Costa Oliveira Taíse dos Santos Alves

Contudo os dados revelam que a atividade sucroalcooleira ainda representa a maior parcela da produção de cana-de-açúcar em Pernambuco. Pois a parte sul da mesorregião responde por $45 \%$ da produção de cana, a parte norte por $31 \%$, a região de Vitória (apesar de contar com apenas 5 municípios) responde a 5\% e as demais regiões juntas somam $19 \%$.

\section{Luta pela terra e processo de regulamentação do assentamento Chico Mendes I}

Diante do cenário de desenvolvimento econômico pautado na monocultura da cana-de-açúcar e na concentração fundiária, a questão agrária em Pernambuco fez desdobrar na mesorregião Zona da Mata inúmeros conflitos territoriais. Como estratégia para pressionar o Instituto Nacional de Colonização e Reforma Agrária (INCRA), que é responsável pela desapropriação de terras improdutivas, destinando-as para fins de reforma agrária, o Movimento dos Trabalhadores Rurais Sem-Terra (MST) articulou camponeses para ocuparem as terras improdutivas da região.

Portanto na década de 90, com o declínio do PROÁLCOOL muitas usinas e antigos engenhos falidos tiveram suas terras ocupadas pelos movimentos sociais de luta pela terra, os quais reivindicavam a efetivação de uma reforma agrária e o cumprimento da função social da terra.

Nessa atmosfera político-econômica em 1997 as terras que faziam parte do Complexo Prado (formado por engenhos), mais precisamente da Usina Santa Tereza, localizada no município de Tracunhaém - PE, foram ocupadas por cerca de 300 famílias sem-terra (210 crianças e 450 adultos), apoiadas pela Comissão Pastoral da Terra (CPT). Os 500 hectares de terra ocupados pelos camponeses estavam há mais de quatro décadas sem serem cultivadas. A CPT é uma entidade sem fins lucrativos ligada à igreja católica - viés da Teologia da Libertação, que trabalha com a população do campo na mediação de conflitos em relação à questão agrária.

As terras reivindicadas pertenciam ao grupo João Santos, que foi detentor de inúmeras usinas e controlou mais da metade da produção canavieira de Pernambuco por aproximadamente 90 anos. Além da produção sucroalcooleira obtinha negócios nas áreas 
Economia camponesa e resistência territorial no assentamento Chico Mendes - PE/Brasil
Cláudio Ubiratan Gonçalves Alexandre Chaves Bezerra

Anamaria Melo Medeiros Andrés Felipe Bernal

Izabela Cristina Gomes da Silva Diego Felipe dos Santos

Maria Rosana da Costa Oliveira Taíse dos Santos Alves

de construção civil, comunicação e aviação. Essas características ancoravam sua alta influência política no estado de Pernambuco e na região Nordeste.

Enquanto as famílias que haviam ocupado as terras eram em sua grande maioria ex-trabalhadores no corte da cana-de-açúcar e moradores de engenhos próximos, que com a crise temiam serem expulsos. Durante o processo de ocupação até a consolidação do assentamento foram desenvolvendo-se vários embates violentos.

Porém nem sempre a violência se desenhava na forma física direta, mas também em ameaças, destruição das lavouras, despejos, perseguições e atentados à vida das lideranças locais e de agentes da CPT. O primeiro despejo ocorreu no mesmo ano da ocupação, depois houve outros dois em 2003 quando o latifundiário solicitou reintegração de posse nas terras do Engenho Prado. Ocasionando na expulsão das famílias mediante ação truculenta da polícia, que destruiu casas, alimentos e a produção cultivada. A situação foi tão extrema que se tornou conhecida de organizações nacionais e internacionais de direitos humanos, conforme constatamos no dizer de Andrade (2005).

O que se pôde presenciar tanto no processo de expulsão dos assentados das áreas do Prado como nos acampamentos na PE-41, oriundos dessa expulsão, foi um verdadeiro ato de violência contra o ser humano. Agressões contra homens, mulheres e crianças, prisões arbitrárias e acima de tudo o descumprimento da lei foram algumas das formas de violência que foram praticadas nas diversas vezes em que a 'lei' buscou pela reintegração de posse da área em litígio em favor do poder do latifúndio e que pela qual passaram as famílias que agora estão acampadas às margens da PE-41. (ANDRADE, 2005).

Então após quase uma década de luta parte da área reivindicada foi desapropriada ainda em 2003, correspondente ao Engenho Penedinho, dando origem ao Assentamento Nova Canaã destinado a uma parte das famílias. As demais famílias continuaram em processo de luta e acampadas até 2005, quando foram desapropriadas as terras de outros três engenhos: Tocos, Papicu e Taquara, que se transformaram nos Assentamentos Chico Mendes (Mapa 1.0) e Ismael Felipe. 
Economia camponesa e resistência territorial no assentamento Chico Mendes - PE/Brasil
Cláudio Ubiratan Gonçalves Alexandre Chaves Bezerra

Anamaria Melo Medeiros Andrés Felipe Bernal

Izabela Cristina Gomes da Silva

Diego Felipe dos Santos

Maria Rosana da Costa Oliveira Taíse dos Santos Alves

Mapa 1: Localização do Assentamento Chico Mendes - Pernambuco, Brasil

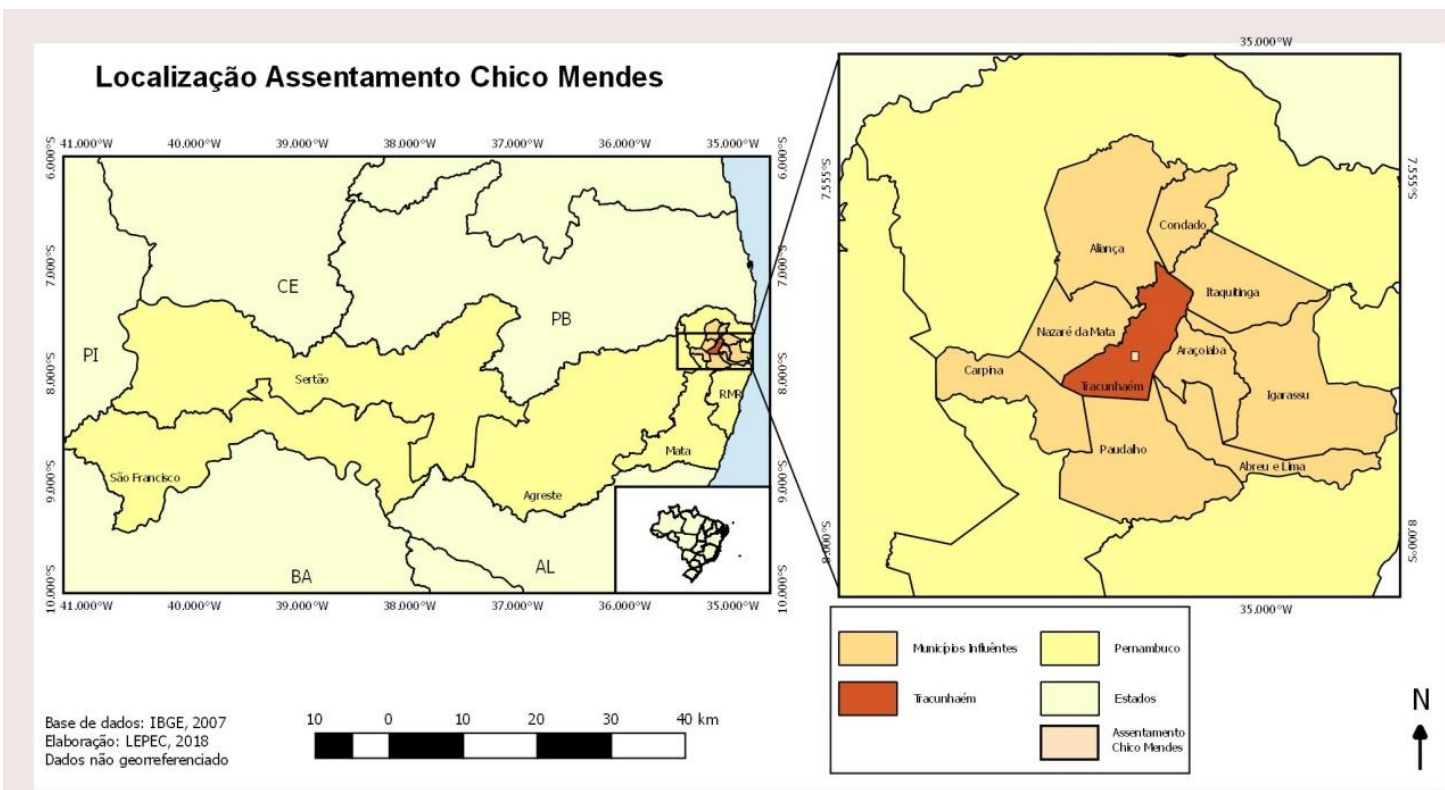

Fonte: IBGE, Área territorial oficial. Consulta por Unidade da Federação (2007). Coordenadas Geográficas coletadas in loco por GPS. ArcGIS 9.3. Organizado por: Taíse Alves - Lepec (2018).

Por conseguinte desde a ocupação da terra até a institucionalização do assentamento as famílias mantiveram suas produções, tanto pra autoconsumo, quanto para comercialização. Assim a condição camponesa se manteve presente, porém há uma preocupação da CPT e das lideranças locais para que os camponeses assentados não voltem a depender da monocultura da cana-de-açúcar. Vendendo sua força de trabalho e sua produção de cana para as usinas.

\section{Economia camponesa, escala de produção e trabalho}

Em contraponto ao modelo hegemônico capitalista, com base em Ploeg (2006) percebemos que o modo de produção camponês se caracteriza a partir de dimensões materiais e imateriais. Entre as características elencamos a localização e a territorialização das unidades produtivas camponesas. Enquanto agricultura capitalista se estabelece através de uma conversão de interesses geopolíticos e fluxos comerciais globais. Já a produção camponesa prioriza o trabalho e consumo familiar. 
Economia camponesa e resistência territorial no assentamento Chico Mendes - PE/Brasil
Cláudio Ubiratan Gonçalves Alexandre Chaves Bezerra

Anamaria Melo Medeiros Andrés Felipe Bernal

Izabela Cristina Gomes da Silva Diego Felipe dos Santos

Maria Rosana da Costa Oliveira Taíse dos Santos Alves

$\mathrm{Na}$ economia camponesa, a quantidade de força de trabalho utilizada na unidade produtiva está correlacionada às práticas de manejo da terra e ao tipo de produção, e não à geração de lucro sobre a exploração do trabalho alheio. Assim contrapondo-se à lógica da revolução verde.

Porém nos anos 1970 esse modelo agrícola-industrial foi implementado e estimulado na América Latina pelos estados-nações, como parte do projeto para alcançar o desenvolvimento capitalista. Objetivando homogeneizar os regimes alimentares e reduzir geneticamente as culturas. (McMichel, 2016 apud COCA, 2016). Assim contaminando a natureza com os agrotóxicos, além de não valorizar a manutenção dos modos de vida camponeses, seus saberes e sua criatividade.

Nesse contexto Ploeg (2006) destaca que o modo de produção camponês é visto por parte de alguns economistas como um retorno ao passado. No entanto ao longo dos últimos anos, este setor vem desenvolvendo tecnologias sociais baseadas no potencial endógeno das unidades produtivas, respeitando o que há de mais importante para a sobrevivência e reprodução da humanidade, a natureza.

Palerm (1980) destaca que os modos de vida camponeses correlacionam os saberes-fazeres populares tradicionais com as práticas ancestrais de manejo da terra e cultivo de alimentos endêmicos (várias espécies de milho, batata, quinoa, entre outros). Pontua-se que apesar do estabelecimento da lógica capitalista de produção na América Latina, não se conseguiu desvanecer as práticas e saberes dos povos camponeses tradicionais e indígenas.

Podemos destacar como potencialidades do modo de produção camponês a produção de alimentos saudáveis e a conservação da natureza atrelada à luta por soberania alimentar. Contrastando com problemas como a fome, insegurança alimentar, alimentação inadequada, degradação da natureza, consumo excessivo de energia e de agrotóxicos, advindos da agricultura agroindustrial capitalista.

Logo a produção camponesa vem sendo inserida em novos mercados e novos circuitos mercantis. Ou seja, novas formas de cooperação local estão sendo visibilizadas, onde os valores imateriais são levados em consideração, como as relações de reciprocidade e de solidariedade entre os camponeses. Confluindo com as ideias sobre 
Economia camponesa e resistência territorial no assentamento Chico Mendes - PE/Brasil
Cláudio Ubiratan Gonçalves Alexandre Chaves Bezerra

Anamaria Melo Medeiros Andrés Felipe Bernal

Izabela Cristina Gomes da Silva Diego Felipe dos Santos

Maria Rosana da Costa Oliveira Taíse dos Santos Alves

'Economia Moral' de Scott (1990), que se centram em aspectos éticos presentes nas relações camponesas.

Elementos dentro do capitalismo, esses sujeitos seguem incorporando técnicas, produzindo 'mercadorias' sem, contudo se tornarem capitalistas face o controle dos meios de produção, e sem tornarem-se proletários. Pois o trabalho familiar ainda é o fundamento de sua reprodução. (PAULINO, 2012, p. 74).

A produção camponesa se dá a partir do "crescimento autônomo" ou "orgânico". Nesse caso a acumulação se subordina aos objetivos socioculturais e o lucro se antepõe ao bem-estar. Enquanto no modo de produção capitalista são implementadas: a mecanização da agricultura, a produção em larga escala, a utilização do pacote tecnológico da revolução verde, o desmatamento, a monocultura, as relações comerciais internacionais e a exploração do trabalho alheio, que gera mais-valia. Para assim obter o aumento do lucro a qualquer custo.

Contudo segundo a abordagem de Ploeg (2008), podemos constatar que a condição camponesa e sua produção vêm sendo fortalecida pelo aumento do número de camponeses. Contrariando a teoria de desaparecimento desta classe social defendida por autores como: Kautsky (1986), Lênin (1982), Prado Jr. (1960), Plekhanov (1976), Mendras (1978), Graziano da Silva (1982). Então ressaltamos a importância de visibilizar as experiências camponesas e caracterizar tanto os pontos em comum, como as particularidades.

\section{Economia Camponesa, comunidade e natureza}

Para analisarmos a economia camponesa existente no assentamento Chico Mendes e sua inserção nos mercados locais, consideramos o marco temporal da institucionalização do assentamento em 2005. Enquanto legitimação da territorialização camponesa advinda do processo de luta pela terra. Pois é a partir da posse da terra, que os camponeses poderão construir territórios camponeses manejando a natureza e produzindo alimentos. 
Economia camponesa e resistência territorial no assentamento Chico Mendes - PE/Brasil
Cláudio Ubiratan Gonçalves Alexandre Chaves Bezerra

Anamaria Melo Medeiros Andrés Felipe Bernal

Izabela Cristina Gomes da Silva Diego Felipe dos Santos

Maria Rosana da Costa Oliveira Taíse dos Santos Alves

Então ressaltamos as dimensões: ambientais, culturais, sociais e políticoeconômicos, que converge com a perspectiva da pluridimensionalidade dos territórios superpostos de Saquet (2015). Assim a comunidade se organizará segundo a ética camponesa sua organização sociocultural (valores, moral) e econômica (produção, consumo, divisão social do trabalho).

Segundo Nash (1979) o contexto social e cultural das operações econômicas camponesas é o que mantém a distância do modelo "moderno". Em confluência com a abordagem de Bartra (2011) propomos tratar a questão da territorialidade e do saber ambiental, enquanto perspectiva metodológica para compreendermos as economias camponesas do Brasil.

Partindo das múltiplas e diferentes relações existentes entre sociedade-natureza. Leff (2009) destaca, que o conhecimento não se forma apenas nas relações de validação com a realidade externa e em uma justificação intersubjetiva do saber. Visando então a construção do saber como parte das experiências dos sujeitos sociais no mundo, levamos em consideração os elementos externos/internos e materiais/imateriais da realidade local.

As unidades produtivas camponesas diferem-se entre si de acordo com a fisiografia, saberes-fazeres familiares, estrutura organizacional, processo de ocupação e uso do território, como também de questões político-econômicas externas e até antecedentes a seu estabelecimento.

Contudo Saquet (2015) coloca que os territórios se formam heterogêneos e superpostos. A partir dessa heterogeneidade são materializadas as territorialidades, nestas há interesses sociais, culturais, econômicos, políticos e ambientais, que dão significados pluridimensionais aos territórios. Assim consideramos relevante abordar os territórios camponeses a partir de sua multidimensionalidade.

Destacamos que o lugar social do campesinato está ligado ao seu processo de lutas e resistências em diferentes espaços e momentos históricos, sendo sua organização fonte de conquistas importantes. Porém, a luta e a resistência camponesa não se encontram limitada ou materializada somente na ação dos movimentos sociais.

Van der Ploeg (2008) aponta que os camponeses possuem um papel crítico na modernidade, representando uma força política antagônica ao capital. Assim sendo, 
Economia camponesa e resistência territorial no assentamento Chico Mendes - PE/Brasil
Cláudio Ubiratan Gonçalves Alexandre Chaves Bezerra

Anamaria Melo Medeiros Andrés Felipe Bernal

Izabela Cristina Gomes da Silva Diego Felipe dos Santos

Maria Rosana da Costa Oliveira Taíse dos Santos Alves

torna-se importante reconhecer as ações de resistência localmente construídas visto que, tendo os camponeses e as camponesas demonstrando grande capacidade de resistência ao construir seus territórios.

Como afirma Fabrini (2006, p. 78). O processo de construção da resistência camponesa parte de um conjunto de características específicas relacionadas à economia, cultura, costumes, política, relações de parentesco e vizinhança, compadrio, relações familiares e de gênero, socialização das crianças, etc.

Portanto serão destacados nesta pesquisa alguns aspectos dessa resistência em relação à lógica capitalista, como as manifestações comunitárias e coletivas próprias do campesinato, a autonomia e o controle do processo produtivo, entre outros.

À vista disso os elementos que constituem essas reflexões teórico-metodológicas, compõem uma série de atributos referentes à realidade pesquisada. Com o enfoque nos processos ligados à condição camponesa e sua influência na reprodução social, formação política, organização e atuação frente situações de conflito por terra/água/território.

\section{Considerações}

Com o desencadeamento desta pesquisa verificamos que o Assentamento Chico Mendes possui atualmente 59 famílias, destas foram entrevistadas 19. O número de pessoas que vivem nas unidades produtivas fica em torno de 2 a 6 pessoas. Os entrevistados originam-se das cidades pernambucanas Abreu e Lima, Paulista e Itaquitinga.

Durante os trabalhos de campo e a vivência nos territórios camponeses, observamos a diversidade da produção camponesa materializada nos cultivos de hortaliças, legumes, frutas, tubérculos, leguminosas e cereais, além da criação de galinhas caipira, caprinos, gado e peixes. No entanto, existem também um investimento e uma área maior destinada à cultura da cana de açúcar, que é vendida para as usinas Santa Teresa e São José.

Como averiguamos na formação territorial da Zona da Mata pernambucana, anteriormente a força de trabalho utilizada nos antigos engenhos era em regime escravista. 
Economia camponesa e resistência territorial no assentamento Chico Mendes - PE/Brasil
Cláudio Ubiratan Gonçalves Alexandre Chaves Bezerra

Anamaria Melo Medeiros Andrés Felipe Bernal

Izabela Cristina Gomes da Silva Diego Felipe dos Santos

Maria Rosana da Costa Oliveira Taíse dos Santos Alves

Todavia atualmente alguns camponeses trabalham por assalariamento sazonal ou por dia de trabalho (diárias) nas usinas, como uma forma de complementar a renda familiar.

Assim dentro dessa economia camponesa existente no Assentamento Chico Mendes foi verificado a produção de culturas para o autoconsumo como: inhame, feijão, milho, batata doce, macaxeira, banana e outros. Já com relação ao escoamento da produção, que é de acordo com a época das safras, existe também a mediação entre produtores e consumidores por meio do atravessador. Esse sujeito constitui-se enquanto intermediador dos núcleos familiares e o mercado local/regional, nessa configuração socioeconômica a produção é vendida no Centro de Abastecimento Alimentar de Pernambuco (CEASA) e em feiras.

Já as feiras dos municípios pernambucanos Araçoiaba, Carpina e Tracunhaém são os principais canais de escoamento da produção camponesa do Assentamento Chico Mendes. No entanto também é destinada aos municípios de Abreu e Lima, Recife e Região Metropolitana do Recife (RMR).

Contudo a maioria das famílias lamenta a relação de dependência com o atravessador, pois se tivessem acesso direto às feiras locais teriam maiores rendimentos. Pois o atravessador compra a produção camponesa por um valor abaixo do valor de mercado e a revende com um preço superior ao que comprou, obtendo assim maior lucro com relação ao camponês produtor de alimento.

Diferente das culturas para o consumo familiar a cana-de-açúcar é inserida no mercado durante todo o ano, pois possui maior valor dependendo dos preços do álcool ou do açúcar, que estão relacionados ao mercado externo através da cotação do dólar. Como relatou um dos entrevistados "Não é que a cana seja ouro, né?" (Camponês assentado, Assentamento Chico Mendes - PE, 2018).

Porém a força de trabalho utilizada na unidade produtiva camponesa constitui-se predominantemente de base familiar e coletiva, mas temporariamente podem ser estabelecidas relações de pagamento por diárias. Como ocorre no período de aplicação dos agrotóxicos, quando há a contratação de ajudantes, além do aluguel de máquinas para a colheita da cana e para transportá-la. 
Economia camponesa e resistência territorial no assentamento Chico Mendes - PE/Brasil
Cláudio Ubiratan Gonçalves Alexandre Chaves Bezerra

Anamaria Melo Medeiros Andrés Felipe Bernal

Izabela Cristina Gomes da Silva Diego Felipe dos Santos

Maria Rosana da Costa Oliveira Taíse dos Santos Alves

Apesar da boa qualidade da terra, a maioria dos entrevistados afirmou ter problemas com pragas em sua produção e que utilizam agrotóxicos. Pois a monocultura da cana, por exemplo, está relacionada ao pacote tecnológico da revolução verde com os agrotóxicos, fertilizantes químicos, corretivos de solo, sementes transgênicas, entre outros.

Nas entrevistas foram evidenciadas as atuais dificuldades enfrentadas pelos camponeses após a conquista da terra. Como a permanência e reprodução dos núcleos familiares no campo. Pois os filhos e filhas desses sujeitos, em sua maioria, não trabalham na produção junto a seus pais. Alguns moram em São Paulo onde estudam e/ou exercem outras profissões.

Outra dificuldade enfrentada é o acesso à água. Os assentados destacam a pouca água destinada para a produção. $\mathrm{O}$ abastecimento se dá a partir de cisternas, poços e tanques. A pouca água e ausência de estrutura de irrigação faz com que as famílias organizem a plantação de acordo com a estação mais chuvosa (o inverno).

Muitos dos camponeses entrevistados exercem outras atividades para complementar a renda das famílias, como pedreiro por exemplo. Devido ao fato de nos últimos quatros anos a comercialização e escoamento da produção diminuiu de modo significativo. Pois as políticas públicas destinadas a comprar alimentos dos assentados, como Plano Nacional de Alimentação (PNAE) e o Programa de Aquisição de Alimentos (PAA) atualmente não estão realizando os pedidos.

A partir dessa crise, podemos entender a dependência dos camponeses do Assentamento Chico Mendes das usinas. Já que atualmente o cultivo da cana é mais rentável para as famílias, tanto na venda como no arrendamento de terras para a sua produção. Poucos camponeses declararam serem aposentados, outros detém sua fonte de renda do programa do governo federal Bolsa Família.

Já ao relatarem sobre serem agricultores, percebemos o orgulho quando tratam sobre a tranquilidade do trabalho, o companheirismo e a solidariedade entre os assentados, assim como a autonomia ao determinar o seu tempo de trabalho. Dentro do contexto de modernização conservadora e de como o capitalismo hoje tem se materializado no campo, a condição camponesa aparece como meio de conseguir 
Economia camponesa e resistência territorial no assentamento Chico Mendes - PE/Brasil
Cláudio Ubiratan Gonçalves Alexandre Chaves Bezerra

Anamaria Melo Medeiros Andrés Felipe Bernal

Izabela Cristina Gomes da Silva Diego Felipe dos Santos

Maria Rosana da Costa Oliveira Taíse dos Santos Alves

autonomia. Possibilitando melhorias socioeconômicas frente a insegurança alimentar e as relações de dependência político/comercial presentes na conjuntura ao qual estes sujeitos estão submersos.

As perspectivas para o futuro não são vistas com animação, principalmente pela ineficiência das políticas públicas e a desorganização e conflitos internos na Associação dos assentados. Ainda que o processo de ocupação do assentamento nos anos de 1990 tenha sido coletivo, não observamos continuidade no processo organizativo, que influencie nas condições de produção e comercialização da mesma maneira para os 59 camponeses.

A partir do título do livro de Ruy Moreira 'mudar para manter exatamente igual' podemos refletir o processo produção do espaço agrário na zona da Mata Pernambucana. Exemplificado pelo assentamento Chico Mendes, percebemos como a história vai se repetindo mudando apenas algumas estratégias das oligarquias, que proporcionam a sujeição dos camponeses em função de uma única cultura.

Agora commodity, a cana- de-açúcar ainda dita as regras nessa mesorregião, o seu valor oscila em função do mercado global, relacionado com a utilização dos agrotóxicos, que são prejudiciais à saúde dos camponeses e da natureza. Contudo a ausência de políticas públicas e organização interna tornam os assentados do Assentamento Chico Mendes muito mais vulneráveis ao mercado externo através das usinas impedindo, que acessem aos mercados locais com sua produção diversificada.

\section{Nota}

\footnotetext{
${ }^{1}$ Projeto realizado com a parceria entre o Laboratório de Estudos e Pesquisa sobre Espaço Agrário e Campesinato (LEPEC), vinculado à Universidade Federal de Pernambuco (UFPE) - Departamento de Ciências Geográficas (DCG) e o Laboratório de Economía, Espacio y Poder (LE2P), vinculado à Facultad de Ciencias Económicas de la Universidad Nacional de Colombia.
}

\section{Referências}

ANDRADE, Manoel Correia et. al. A Luta pela Terra em Pernambuco. In: Anais do PIBIC./UFPE. Recife: 2005. 
Economia camponesa e resistência territorial no assentamento Chico Mendes - PE/Brasil
Cláudio Ubiratan Gonçalves Alexandre Chaves Bezerra Anamaria Melo Medeiros Andrés Felipe Bernal Izabela Cristina Gomes da Silva Diego Felipe dos Santos Maria Rosana da Costa Oliveira Taíse dos Santos Alves

ANDRADE, M. C. de; ANDRADE, S. Mª C. de A Cana-de-Açúcar na região da mata pernambucana: reestruturação produtiva na área canavieira de Pernambuco nas décadas de 80 e 90. Recife: Editora da Universidade Federal de Pernambuco, 2001.

BARTRA, A. B. V. Os novos camponeses: leituras a partir do México profundo, tradução Maria Angélica Pandolfi, revisão técnica Bernardo Mançano Fernandes, João Pedro Stédile, Silvia Beatriz Adoue. - São Paulo: Cultura Acadêmica, Cátedra Unesco de Educação do Campo e Desenvolvimento Rural, 2011.

BRANDÃO, C. R.; BORGES, M. A pesquisa participante: um momento da educação popular. Rev. Ed. Popular, Uberlândia, v. 6, p.51-62. jan./dez. 2007.

CASTRO, J. de Geografia da Fome: o dilema brasileiro: pão ou aço, Josué de Castro. Rio de Janeiro: Edições Antares, 1984.

CHAYANOV, A. Teoria dos sistemas econômicos não-capitalistas, Daniel Thorner, Basile Kerblay, R.E.F. Smith, 1924.

CHAYANOV, A. La Organización de la unidad económica campesina. Buenos Aires: Ediciones Nueva Visión, 1974.

COCA, E.L. de Freitas. 20 anos de proposta de soberania alimentar: construindo um regime alimentar alternativo. Revista NERA. Ano 19, n. 32 - edição especial, 2016, p.14-33. Disponível:

http://revista.fct.unesp.br/index.php/nera/article/view/4789/3486. Acesso em: 06 nov. 2017.

CPT [internet] Comissão Pastoral da Terra. Secretaria Nacional, Goiânia - GO, Brasil, 2018. Disponível: https://www.cptnacional.org.br/ Acesso em: Jul. 2018.

CPT. Prado : a re-volta dos camponeses e das camponesas : a luta e a conquista da terra dos trabalhadores e das trabalhadoras sem terra no engenho Prado 1997-2005 /

[Comissão Pastoral da Terra]. - Recife : Ed. Universitária da UFPE, 2013.

DUARTE, C. Desencuentros territoriales: la emergencia de los conflictos interétnicos e interculturales en el departamento del Cauca. Bogotá: Instituto Colombiano de Antropologia e História. 2015.

FABRINI, João Edimilson. A escala da luta e resistência camponesa. Geosul, v.21, n 42, 2006.

GRAZIANO DA SILVA, J. A modernização dolorosa. Rio de Janeiro, Ed. Zahar, 1982. 
Economia camponesa e resistência territorial no assentamento Chico Mendes - PE/Brasil
Cláudio Ubiratan Gonçalves Alexandre Chaves Bezerra

Anamaria Melo Medeiros Andrés Felipe Bernal

Izabela Cristina Gomes da Silva

Diego Felipe dos Santos

Maria Rosana da Costa Oliveira Taíse dos Santos Alves

GRAZIANO DA SILVA, José \& STOLCHE, Verena. A questão agrária. São Paulo: Ed. Brasiliense, 1981.

IBGE [internet]. Instituto Brasileiro de Geografia e Estatística, Governo Federal do Brasil, Brasília - DF, 2010. Disponível: https://ww2.ibge.gov.br/home/default.php Acesso em: 15 Ago. 2018.

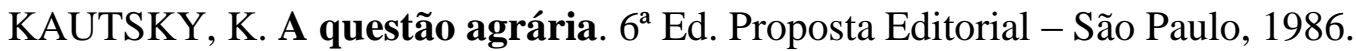

LEFF, E. Complexidade, Racionalidade Ambiental e Diálogo de Saberes, Revista Educação \& Realidade, UFRGS, Porto Alegre, 34(3): 17-24, set/dez 2009.

LÊNIN, V. I. O desenvolvimento do capitalismo na Rússia - Abril Cultural - São Paulo, 1982.

LÓPEZ-RIDAURA, S.; MASERA, O.; ASTIER, M. Evaluating the Sustainability of integrated Peasantry Systems: The MESMIS Framework. Ileia Newsletter, Dez., p. 28-30, 2000.

MARANGONI, A. M. C. Questionários e entrevistas - algumas considerações. In: VENTURI, L. A. B. (Org.) Praticando a geografia: técnicas de campo e laboratório em geografia e análise ambiental. São Paulo: Oficina de textos, 2005, p. 167-174.

MEDEIROS, Anamaria Melo. Faz escuro, mas eu canto: Disputa Territorial e Resistência Camponesa no Engenho Barra do Dia. Dissertação (Mestrado) Universidade Federal de Pernambuco. CFCH. Programa de Pós-Graduação em Geografia, Recife, 2017, 164p.

MENDRAS, H. Sociedades camponesas, Rio de Janeiro, ZAHAR EDITORES, 1978. MESMIS. Marco de Evaluación de Sistemas de Manejo Incorporando Indicadores de Sustentabilidad. Disponível em: mesmis.gira.org.mex Acesso em: Junho de 2018.

NASH, M. El mercado y las economías campesinas indígenas. In: SHANIN, T. (Comp.) Campesinos y sociedades campesinas, tradução de Eduardo Suárez, 2, México, Fondo de Cultura Económica, 1979.

PALERM, A. Antropólogos y campesinos: los límites del capitalismo. Antropología y Marxismo, México: Nueva Imagen, 1980.

PAULINO, Eliane Tomiasi. Por uma Geografia dos Camponeses. 2 ed. São Paulo: Editora UNESP, 2012. 
Economia camponesa e resistência territorial no assentamento Chico Mendes - PE/Brasil
Cláudio Ubiratan Gonçalves Alexandre Chaves Bezerra Anamaria Melo Medeiros Andrés Felipe Bernal Izabela Cristina Gomes da Silva Diego Felipe dos Santos Maria Rosana da Costa Oliveira Taíse dos Santos Alves

PLEKHANOV, G. V. Cuestiones fundamentales del marxismo, Barcelona:

Fontamara, 1976. In: SEVILLA-GUZMÁN, E.; MOLINA, M. Sobre a evolução do conceito de campesinato, São Paulo: Expressão Popular, 2013.

PLOEG, J. D. Van Der. Camponeses e Impérios Alimentares: lutas por autonomia e sustentabilidade na era da globalização. Série Estudos Rurais, Porto Alegre: UFRGS, 2008. $372 \mathrm{p}$.

PLOEG, J. D. Van Der. O modo de produção camponês revisitado. In: SCHNEIDER, Sérgio (Org.). A diversidade da agricultura familiar. Porto Alegre: UFRGS, 2006.

PRADO Jr., C. (1960). Contribuição para análise da questão agrária no Brasil. In: VEIGA, José Eli da. (Org.). A questão agrária. São Paulo: Brasiliense, 2000, p. 1585.

SAQUET, M. A. Por una geografía de las territorialidades y las temporalidades: una concepción multidimensional orientada a la cooperación y el desarrollo territorial, Facultad de Humanidades y Ciencias de la Educación, $1^{\text {a }}$ edición en castellano, Universidad Nacional de La Plata, La Plata - Argentina, 2015.

SCOTT, J. C. Los dominados y el arte de la resistência. México: Ediciones Era, 1990.

SHANIN, T. La clase incómoda: Sociología política del campesinado en una sociedad en desarrollo - Rusia (1910-1925) - Alianza Editorial - Madrid, 1983. 